\title{
Tissue specific promoters improve specificity of AAV9 mediated transgene expression following intra-vascular gene delivery in neonatal mice
}

\author{
Christina A Pacak ${ }^{\dagger}$, Yoshihisa Sakai ${ }^{\dagger}$, Bijoy D Thattaliyath, Cathryn S Mah* \\ and Barry J Byrne*
}

Address: Powell Gene Therapy Center, College of Medicine, University of Florida, 1600 SW Archer Road, Gainesville, FL 32610-0266, USA

Email: Christina A Pacak - christina.pacak@childrens.harvard.edu; Yoshihisa Sakai - ysakai@ufl.edu; Bijoy D Thattaliyath - bijoy@ufl.edu; Cathryn S Mah* - cmah@ufl.edu; Barry J Byrne* - bbyrne@ufl.edu

* Corresponding authors †Equal contributors

Published: 23 September 2008

Genetic Vaccines and Therapy 2008, 6:13 doi:10.1 I86/1479-0556-6-13

This article is available from: http://www.gvt-journal.com/content/6/1/13

(C) 2008 Pacak et al; licensee BioMed Central Ltd.

This is an Open Access article distributed under the terms of the Creative Commons Attribution License (http://creativecommons.org/licenses/by/2.0), which permits unrestricted use, distribution, and reproduction in any medium, provided the original work is properly cited.
Received: 10 June 2008

Accepted: 23 September 2008

\begin{abstract}
The AAV9 capsid displays a high natural affinity for the heart following a single intravenous (IV) administration in both newborn and adult mice. It also results in substantial albeit relatively lower expression levels in many other tissues. To increase the overall safety of this gene delivery method we sought to identify which one of a group of promoters is able to confer the highest level of cardiac specific expression and concurrently, which is able to provide a broad biodistribution of expression across both cardiac and skeletal muscle. The in vivo behavior of five different promoters was compared: CMV, desmin (Des), alpha-myosin heavy chain $(\alpha-M H C)$, myosin light chain 2 (MLC-2) and cardiac troponin C (cTnC). Following IV administration to newborn mice, LacZ expression was measured by enzyme activity assays. Results showed that rAAV2/9-mediated gene delivery using the $\alpha-M H C$ promoter is effective for focal transgene expression in the heart and the Des promoter is highly suitable for achieving gene expression in cardiac and skeletal muscle following systemic vector administration. Importantly, these promoters provide an added layer of control over transgene activity following systemic gene delivery.
\end{abstract}

\section{Findings}

When developing gene therapy, it is important to minimize adverse responses to protein expression in unnecessary sites by restricting transgene expression to areas where it is most desirable. This confinement can be tissue restricted expression such as in the heart, or limited expression to a combination of tissues such as those affected in the muscular dystrophies.

One way to control the site of transgene expression is through choice of physical delivery route [1]. Direct injections into a specific tissue help to concentrate transduc- tion to that exact location. However, it is often difficult to achieve a broad and even biodistribution of expression across an entire organ. Adeno-associated virus (AAV) has emerged as an extremely versatile vehicle for gene delivery due to its persistence and ability to transduce a variety of tissues [2-5]. Investigators have demonstrated successful intravenous (IV) AAV delivery via the superficial temporal vein in newborn mice or the jugular vein, portal vein and tail vein in adult mice [6-9]. Systemic IV delivery routes are particularly well suited when an extensive biodistribution of transgene expression is advantageous. In order to achieve thorough perfusion in one specific tissue but not 
throughout the entire body, greater control may be required.

In addition to the physical delivery route, another way to confine expression is by choosing a gene delivery vehicle with a high natural tropism for the tissue of interest. Several groups have demonstrated the unique ability of the AAV9 capsid to yield extraordinarily high levels of transgene expression in the heart [8-11]. Each of these groups using their respective delivery routes and detection systems also observed various levels of expression in other tissues. These data demonstrate that selection of a particular delivery vehicle alone is not enough to isolate transgene expression.

One approach to further increase specificity is to select a promoter that naturally drives expression of a particular gene in the tissue/s of interest. The objective of the current study was to identify which one of a group of promoters confers the greatest degree of cardiac specific expression and concurrently, which provides a broad biodistribution of expression across both cardiac and skeletal muscle.

Five promoters were compared: cytomegalovirus immediate-early gene promoter (CMV), human desmin (Des), human alpha-myosin heavy chain ( $\alpha$-MHC), rat myosin light chain 2 (MLC-2) and human cardiac troponin $\mathrm{C}$ (cTnC) (Figure 1A). Each promoter-LacZ construct was flanked by the inverted terminal repeats of AAV2 and packaged into the AAV9 capsid to yield rAAV2/9-promoter-LacZ. The constructs were tested by transfection and subsequently infection of both differentiated and undifferentiated $\mathrm{C} 2 \mathrm{C} 12$ cells and a previously described immortalized cardiomyocyte line [12] to confirm promoter function (data not shown).

The CMV construct (690 base pairs [bp]) used in these experiments was from Stratagene ${ }^{\circledast}$ (rAAV2/9-CMV-LacZ). It contains 5 cyclic AMP response-element binding protein (CRE-BP - a member of the leucine zipper family of transcription factors) binding sites as well as 4 NFkappaB binding sites. The CMV promoter confers virtually ubiquitous expression throughout the body except in the liver where it becomes inactive once the initial inflammatory phase passes [13]. The goal of this study was to identify alternatives to the CMV promoter.

The human desmin construct (354 bp) described in this study (rAAV2/9-Des-LacZ) contains both a myocyte specific enhancer factor 2 (MEF2) and a MyoD enhancer element. A TATA box was also added to increase transcription specificity. The primers were designed using the Catalogue of Regulatory Elements [14]. This promoter normally drives expression of desmin, a major intermediate filament protein essential for maintaining the func- tional and structural integrity of muscle [15]. Analysis of human tissues has revealed desmin expression in cerebellum, endometrium, skeletal muscle, neuronal cells of the lateral ventricle and heart [16]. Desmin may be a useful promoter to incorporate when performing systemic transgene delivery in myopathies. Diverse targets could include cardio skeletal muscle and even neurons.

The human $\alpha$-MHC promoter (363 bp) (rAAV2/9- $\alpha$ MHC-LacZ) construct contains a MEF2 region, a PRE-D sequence (tandem GATA sites separated by $4 \mathrm{bp}$ ), and 2 CArG elements. The primers were designed using the Catalogue of Regulatory Elements [14]. Myosin heavy chain is the most abundant component of the cardiac sarcomere [17]. We therefore hypothesized that it would be a highly specific cardiac promoter. The $\alpha$-MHC protein is a "fast" ATPase myosin and is located in the thick filaments of myofibrils. It is important for cardiomyocyte contraction and relaxation [18]. In mice, the $\alpha$-MHC protein is expressed in cardiac atrium and ventricles as well as skeletal muscle. In humans, $\alpha$-myosin expression is restricted to the atria, and the $\beta$-MHC isoform ("slow" ATPase myosin) is the most predominant in ventricles [17]. Previous in vitro experiments with rat neonatal cardiomyocytes and mouse studies have shown that the MHC promoter preferentially expresses in cardiac tissue more than skeletal muscle [19].

The promoter incorporated into the rat MLC construct described here, (479 bp) (rAAV2/9-MLC-LacZ) has been previously described by Henderson $e t$. al. and was originally designed from cardiac MLC-2 [20]. While various isoforms exist, the cardiac MLCs can be divided into 2 types: MLC-1, non-phosphorylatable and MLC-2, phosphorylatable. $\mathrm{Ca}^{2+}$ dependent phosphorylation of MLC-2 by MLC kinase provides an important a regulatory function in the contraction of cardiac, skeletal and smooth muscle [20]. Two different isoforms of MLC-2 are typically expressed in the atria and ventricles of the mammalian heart during embryonic development and maturation, and later in the adult heart [21]. The ratderived MLC promoter characterized here contains a CArG box as well as a MyoD enhancer sequence.

The human cTnC construct (rAAV2/9-cTnC-LacZ) (175 bp) contains 2 cardiac enhancer factor (CEF) sites. The primers for this promoter were designed using the Catalogue of Regulatory Elements [14]. The CEF sites of the human cTnC bind cardiac specific nuclear proteins [22]. CEF-1 specifically binds the GATA- 4 protein in addition to a currently uncharacterized nuclear protein complex that is also bound by CEF-2. The cardiac troponin C (cTnC) gene produces identical transcriptsin both slow twitch skeletal muscle as well as the heart. It binds $\mathrm{Ca}^{2+}$ and prevents actin-myosin interaction in resting muscle. 

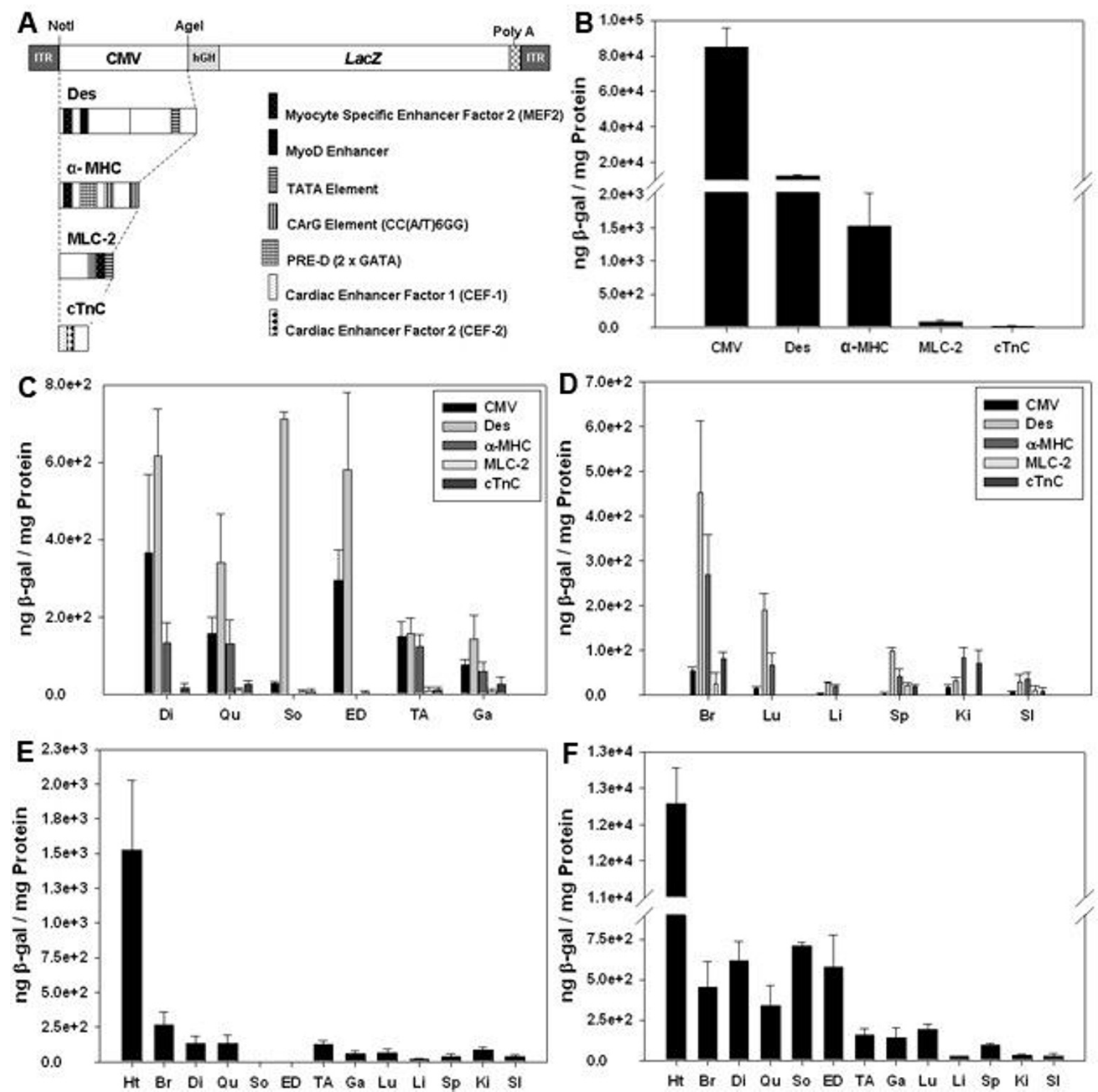

Figure I (see legend on next page) 
Figure I (see previous page)

A) Construct Diagrams. Promoters were switched into the backbone by replacement of the CMV promoter between the first Notl and Agel sites. The Des construct was created using primers against human genomic DNA (forward [F] Des enhancer primer containing Notl) ATA AGA ATG CGG CCG CAC CCA TGC CTC CTC AGG TA, (reverse [R] Des enhancer primer containing Xhol) CCG CTC GAG GGT GGG GCC TCA AGT TTA T, ([F] Des promoter primer containing Xhol) CCG CTC GAG ATA ACC AGG GCT GAA AGA, ([R] Des promoter primer containing Agel) TGTA CCG GTG ACG GCG CGG GCG AGG CT. The $\alpha-M H C$ construct was created by amplifying human genomic DNA: ([F] containing Notl) ATA AGA ATG CGG CCG CCC AGT TGT TCA ACT CAC CCT TCA and ([R] containing Agel) TGT ACC GGT GGG TTG GAG AAA TCT CTG ACA GCT. The MLC-2 construct was created by replacing the backbone with the previously described rat MLC-2 promoter[20]. ([F] containing Notl) ATA AGA ATG CGG CCG CGA CCC AGA GCA CAG AGC ATC GT ([R] containing Agel) TGT ACC GGT GAA TTC AAG GAG CCT GCT. The cTnC construct was created by amplifying human genomic DNA: ([F] containing Notl) ATA AGA ATG CGG CCG CCA GCC TGA GAT CAC TGG GAC CAG A ([R] containing Agel) TGT ACC GGT CCA TGC TGG CGG CTC ACA GGA. $5 \times 10^{10} \mathrm{vg} / \mathrm{mouse}$ was administered $(\mathrm{n}=6$ per promoter group) [23]. Tissue lysates were assayed using the Galacto-Star chemiluminescence reporter gene assay system (Tropix, Inc., Bedford, MA, USA). Protein concentrations were determined using the Bio-Rad DC protein assay kit (Bio-Rad, Hercules, CA, USA). B) $\beta$ galactosidase $(\beta$-gal) expression levels show that CMV provides the greatest amount of expression in the heart followed by Des and $\alpha$-MHC. C) $\beta$-gal levels in skeletal muscle including the diaphragm were highest in mice that were administered the Des construct. ( $\mathrm{Di}$, diaphragm; Qu, quadriceps; So, soleus; ED, extensor digitorum longus; TA, tibialis anterior; Ga, gastrocnemius) D) Evaluation by $\beta$-gal assay of non-heart, non-skeletal muscle tissues revealed highest expression levels in brain and lung from mice injected with the Des construct. (Ht, heart; Br, brain; Lu, lung; Li, liver; Sp, spleen; Ki, kidney; SI, small intestine) E) and F) $\beta$-gal levels and biodistribution profiles from $\alpha-M H C$ and Des construct injected mice (respectively).

We hypothesized that elements from the troponin promoter, which is found in both heart and skeletal muscle, would drive expression in all striated muscle.

$\mathrm{BALB} / \mathrm{c}$ neonatal mice received $5 \times 10^{10}$ vector genomes (vg) of each vector via single injections to the superficial temporal vein ( $n=6$ per promoter group). After 4 weeks the tissues were harvested and expression levels were evaluated by $\beta$-galactosidase enzyme assay. The highest levels of expression were observed in hearts of animals injected with the CMV, Des or $\alpha-M H C$ constructs (Figure 1B). Expression levels in hearts of animals injected with viruses containing either the MLC-2 or cTnC promoters were comparatively weak.

Analysis of expression in skeletal muscles including the diaphragm (Figure $1 \mathrm{C}$ ) revealed the strongest $\beta$-galactosidase expression levels were from the Desmin promoter. The CMV promoter showed the next highest expression levels followed by the other promoters. Analysis of nonheart, non-skeletal muscle tissues (Figure 1D) showed that the Des promoter produced the highest expression levels in the brain.

Comparing biodistribution profiles of each promoter individually showed that of those included in this study, the $\alpha-\mathrm{MHC}$ is the most cardiac specific (Figure 1E) and the Des construct is well suited for achieving transgene expression in both heart and skeletal muscle (Figure 1F). Importantly, the Des promoter also showed expression levels in the brain that were similar to those found in muscle. This is a key attribute when gene therapy is applied to Pompe
Disease where a neuronal as well as a muscular component has been observed [7].

The biodistribution of viral vector genomes from mice injected with the Des construct was assessed by real time PCR on DNA isolated from each tissue. This measurement is indicative of viral genome location and is independent of the specific promoter being delivered. The vector genome biodistribution profile was very similar to that previously described for AAV9 [8] confirming that the variance in expression profiles result from the different promoters being employed. Heart contained the highest concentration at $19 \pm 2$ copies per cell followed by the diaphragm with approximately $0.13 \pm 0.007$ copies per cell. All other tissues contained less than 0.01 copies per cell.

Ultimately, these data serve as a characterization of 5 different promoters and their respective behavior in vivo following AAV9 mediated gene delivery. Our data indicate that the $\alpha$-MHC promoter confers the most cardiac specific expression and that the Des promoter provides expression in a variety of tissues. The combined use of application tailored promoters and delivery vehicles with well-understood tropisms augment the control investigators have over expression of their transgene of interest and thereby increase the over-all safety of therapeutic gene delivery.

\section{Competing interests}

The Johns Hopkins University, the University of Florida, B.J.B., C.A.P., and C.S.M. could be entitled to patent royalties for inventions described in this article. 


\section{Authors' contributions}

CAP participated in the design of the study, performed the injections, ran the $\beta$-galactosidase enzyme detection assays and drafted the manuscript. YS designed and cloned the plasmids and harvested tissues. BDT performed the RNA transcript analysis and helped to draft the manuscript. CSM participated in the design of the study and helped to draft the manuscript. BJB participated in the design of the study and reviewed the manuscript. All authors read and approved the final manuscript.

\section{Acknowledgements}

We would like to express our gratitude to Mark Potter, the University of Florida Powell Gene Therapy Center (PGTC) and Irene Zolotukhin for providing technical expertise in producing the viruses used in this study. We would also like to thank Stacy Porvasnik for assisting with animal work and Dr. Steven Potter (Children's Hospital Medical Center, Cincinnati, Ohio) for providing the immortalized line of cardiomyocytes. This work was supported in part by an American Heart Association Pre-doctoral Fellowship Award-Florida and Puerto Rico Affiliate (to CAP), the NIH National Heart, Lung, and Blood Institute grant POI HL594I 2; National Institute of Diabetes and Digestive and Kidney Diseases grant POI DK58327; AT-NHLBI-U0I HL69748; and the AHA National Center (to C.S.M.).

\section{References}

I. Thierry AR, Lunardi-Iskandar Y, Bryant JL, Rabinovich P, Gallo RC, Mahan LC: Systemic gene therapy: biodistribution and longterm expression of a transgene in mice. Proc Natl Acad Sci USA 1995, 92:9742-9746.

2. Clark KR, Sferra TJ, Johnson PR: Recombinant adeno-associated viral vectors mediate long-term transgene expression in muscle. Hum Gene Ther 1997, 8:659-669.

3. Kessler PD, Podsakoff GM, Chen X, McQuiston SA, Colosi PC, Matelis LA, Kurtzman GJ, Byrne BJ: Gene delivery to skeletal muscle results in sustained expression and systemic delivery of a therapeutic protein. Proc Natl Acad Sci USA 1996, 93: | 4082-1 4087.

4. Podsakoff G, Wong KK Jr, Chatterjee S: Efficient gene transfer into nondividing cells by adeno-associated virus-based vectors. J Virol 1994, 68:5656-5666.

5. Xiao X, Li J, Samulski RJ: Efficient long-term gene transfer into muscle tissue of immunocompetent mice by adeno-associated virus vector. I Virol 1996, 70:8098-8I 08.

6. Mah C, Cresawn KO, Fraites TJ Jr, Pacak CA, Lewis MA, Zolotukhin I, Byrne B]: Sustained correction of glycogen storage disease type II using adeno-associated virus serotype I vectors. Gene Ther 2005, I 2: 1405-1409.

7. Mah C, Pacak CA, Cresawn KO, Deruisseau LR, Germain S, Lewis MA, Cloutier DA, Fuller DD, Byrne BJ: Physiological Correction of Pompe Disease by Systemic Delivery of Adeno-associated Virus Serotype I Vectors. Mol Ther 2007, I5:50I-507.

8. Pacak CA, Mah CS, Thattaliyath BD, Conlon TJ, Lewis MA, Cloutier $\mathrm{DE}$, Zolotukhin I, Tarantal AF, Byrne BJ: Recombinant adenoassociated virus serotype 9 leads to preferential cardiac transduction in vivo. Circ Res 2006, 99:e3-9.

9. Inagaki K, Fuess S, Storm TA, Gibson GA, McTiernan CF, Kay MA, Nakai H: Robust systemic transduction with AAV9 vectors in mice: efficient global cardiac gene transfer superior to that of AAV8. Mol Ther 2006, 14:45-53.

10. Sarkar R, Mucci M, Addya S, Tetreault R, Bellinger DA, Nichols TC Kazazian $\mathrm{HH}$ Jr: Long-term efficacy of adeno-associated virus serotypes 8 and 9 in hemophilia a dogs and mice. Hum Gene Ther 2006, 17:427-439.

II. Vandendriessche T, Thorrez L, Acosta-Sanchez A, Petrus I, Wang L, Ma L, L DEW, Iwasaki Y, Gillijns V, Wilson JM, et al.: Efficacy and safety of adeno-associated viral vectors based on serotype 8 and 9 vs. lentiviral vectors for hemophilia B gene therapy. Thromb Haemost 2007, 5:16-24.
12. Brunskill EW, Witte DP, Yutzey KE, Potter SS: Novel Cell Lines Promote the Discovery of Genes Involved in Early Heart Development. Developmental Biology 200I, 235:507-520.

13. Loser P, Jennings GS, Strauss M, Sandig V: Reactivation of the previously silenced cytomegalovirus major immediate-early promoter in the mouse liver: involvement of NFkappaB. Virol 1998, 72: 180-190.

14. Catalogue of Regulatory Elements [http://www.cbil.upenn.edu/ MTIR/TOC.html]

15. Paulin D, Li Z: Desmin: a major intermediate filament protein essential for the structural integrity and function of muscle. Exp Cell Res 2004, 30 I: I-7.

16. Wallenberg: Human Protein Atlas. 2006.

17. James J, Osinska H, Hewett TE, Kimball T, Klevitsky R, Witt S, Hall DG, Gulick J, Robbins J: Transgenic over-expression of a motor protein at high levels results in severe cardiac pathology. Transgenic Res 1999, 8:9-22.

18. Kim SJ, lizuka K, Kelly RA, Geng YJ, Bishop SP, Yang G, Kudej A McConnell BK, Seidman CE, Seidman JG, Vatner SF: An alpha-cardiac myosin heavy chain gene mutation impairs contraction and relaxation function of cardiac myocytes. Am J Physiol I999, 276: $\mathrm{HI}$ 780-I787.

19. Aikawa R, Huggins GS, Snyder RO: Cardiomyocyte-specific gene expression following recombinant adeno-associated viral vector transduction. J Biol Chem 2002, 277:18979-I8985.

20. Henderson SA, Spencer M, Sen A, Kumar C, Siddiqui MA, Chien KR Structure, organization, and expression of the rat cardiac myosin light chain-2 gene. Identification of a 250-base pair fragment which confers cardiac-specific expression. J Biol Chem 1989, 264: $18142-18148$.

21. Kelly R, Buckingham M: Manipulating myosin light chain 2 isoforms in vivo: a transgenic approach to understanding contractile protein diversity. Circ Res 1997, 80:75I-753.

22. Ip HS, Wilson DB, Heikinheimo M, Tang Z, Ting CN, Simon MC, Leiden JM, Parmacek MS: The GATA-4 transcription factor transactivates the cardiac muscle-specific troponin $C$ promoterenhancer in nonmuscle cells. Mol Cell Biol 1994, 14:75I7-7526.

23. Sands MS, Barker JE: Percutaneous intravenous injection in neonatal mice. Lab Anim Sci 1999, 49:328-330.

Publish with Bio Med Central and every scientist can read your work free of charge

"BioMed Central will be the most significant development for disseminating the results of biomedical research in our lifetime. "

Sir Paul Nurse, Cancer Research UK

Your research papers will be:

- available free of charge to the entire biomedical community

- peer reviewed and published immediately upon acceptance

- cited in PubMed and archived on PubMed Central

- yours - you keep the copyright 